\title{
Evolutional Steps toward the Post-Western/Non-Western Movement in Japan
}

\author{
Hidenobu Jinnai \\ Graduate School of Engineering and Design, Hosei University, Tokyo, Japan \\ Email:jinnai@h-jinnai.jp
}

\begin{abstract}
This paper examines Japanese past from the beginning of the Meiji era until today in a historical perspective in order to make easier to understand from a post-Western/non-Western approach the processes that took place in this period of time. Initially, Japan began to adopt Western ideologies, technologies and systems to build a modern nation and to make the development of modern architecture and city planning possible. These models continued to be looked at for a long time. From the 1970s, when the years of sustained economic growth came to an end, Japanese began to dismiss the idea of reaching and overtaking the West gradually. They began to search for a Japanese identity. The richness of nature, the particular Japanese history and its specific culture developed through delicate senses were reevaluated. At the same time, the cultural values of the historic urban space and townscape were rediscovered. Finally, the paper examines the idea and method of Machizukuri (bottom-up town-making) originated and developed thanks to the physical and social resources historically accumulated in the Japanese cities.
\end{abstract}

KEYWORDS Westernisation, urban history, townscape, bottom-up, Machizukuri, cultural identity, spatial anthropology, satoyama

Received July 24, 2017; accepted August 21, 2017.

\section{Introduction}

Paolo Ceccarelli, who continues to work energetically in various parts of the non-Western world, has engaged deeply with Japanese architects and urban planners. When he visited Japan last autumn, he raised some truly stimulating questions, aimed at stirring international debate on the concepts of 'post-Western' and 'non-Western'. Many Japanese, who constantly think about these concepts in their pursuit of research, planning, and design work, agree with his ideas. So, taking the opportunity for a deliberate and theoretical discussion of this problem, several of us got together to exchange opinions on the subject. This article is a summary of our discussion.

\section{From the Meiji Enlightenment to Expo Osaka 1970}

Firstly, to understand the situation of Japan in connection with this issue, we want to start with a historical overview. In the period of 'civilisation and enlightenment' in the early Meiji era (1868-1912), Japan began actively adopting Western ideologies, technologies, and systems in its effort to build a modern nation, and for a long time, it continued to look to these as models. Like other nonWestern countries, Japan equated modernisation with Westernisation.

The fields of architecture and urban design certainly followed this pattern. During the Meiji era, new and brilliant urban spaces that promoted the nation-building project in accordance with Western ideas were created in Tokyo, which had become Japan's capital. And they were distinctly different to the urban spaces typical of the Edo era. These included Ginza 'Brick Town' (1872) by Englishman Thomas James Waters; the Ministry of Justice Building near Hibiya Park (1886) by the Germans Hermann Gustav Louis Ende and Wilhelm Böckmann, and the Marunouchi Office District (1894), began by Englishman Josiah Conder (Figure 1). 


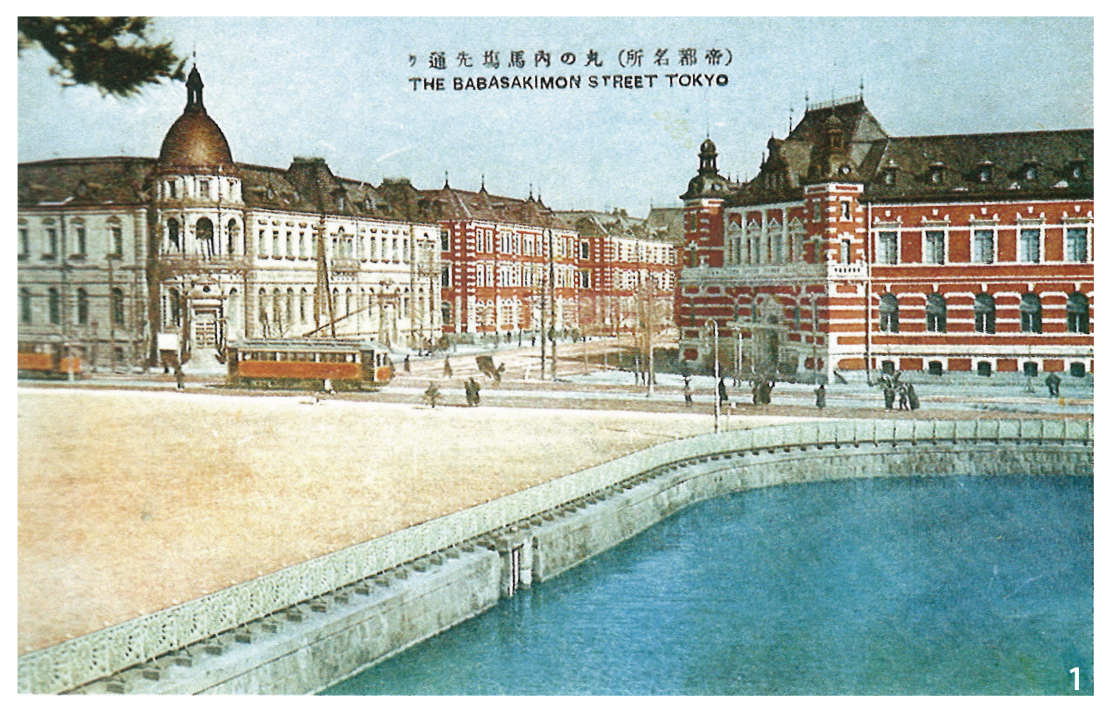

Figure 1 Late Meiji era view of Babasaki street in Marunouchi (Source: Mituhiko Ogata 1980). Figure 2 General view of Motomachi Park (Source: Tokyo Municipal Office 1935).

Figure 3 Slide and sandbox in Motomachi Park (Source: the author).

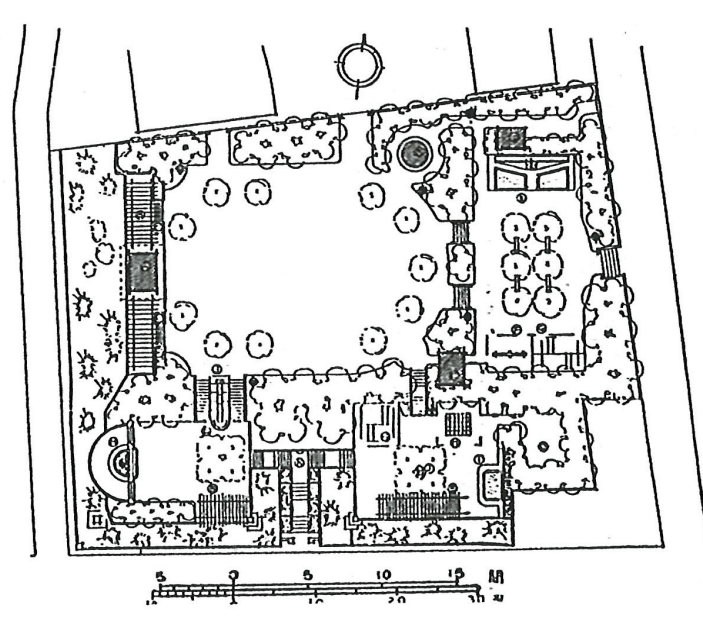

Yearning for the West remained strong. In the early Showa era, during the period of recovery following the Great Kanto Earthquake of 1923, modern ideas and designs, modelled after Western architecture and urban planning had penetrated far and wide across Tokyo. All Western methods had become established as models, e.g., small public parks (Figure 2, Figure 3), hiroba (open public spaces), and modern apartment buildings in the city centre and shitamachi (low-lying, downtown) areas, as well as the city of Den-en-chofu (Figure 4 ) on the outskirts of Tokyo, modeled on the English 'garden suburb' concept. The post-war 'new towns' could also be considered a Western borrowing.

In the post-war democratic era, there was a strong push to create citizen-centric cities. However, for a long time, Japan was influenced strongly by the ideas in Max Weber's 'typology of cities. There was a tendency to accept uncritically Weber's assertion that Western cities were ideal cities, whereas the cities of East Asia, including Japan, tended to lack citizens' autonomy. Thus, for a long time, Japanese

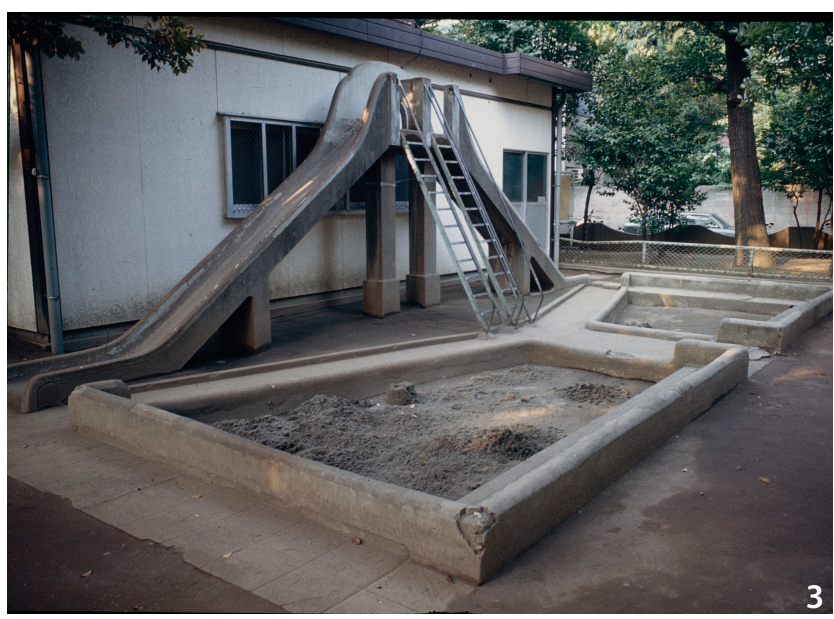

were unable to free themselves of an inferiority complex about Western cities. Very much for this reason, in the 1960s Japan rediscovered the virtues of its port cities such as Sakai and Niigata, which seemed to promote citizens' autonomy in a Western way. These cities were praised for the way they cultivated the civic spirit of their leading citizens. At the same time, attention was paid to how the spirit of citizens' autonomy was developed at the heart of Buddhist temples in temple districts such as Imaicho in Nara Prefecture.

The yearning for Western cities continued after the war, and many citizens' squares were built outside municipal offices based on 'enlightenment' ideals. Yet, public spaces that were useful to the masses were still a rarity. Partly for this reason, the tradition of 'public squares' was said to be nonexistent in Japan, but this view was challenged by architectural historian Teiji Ito (with support from young architects such as Arata Isozaki), who worked to rediscover Japan's unique forms of hiroba (open public space) -quite different to those of Western cities. The August 


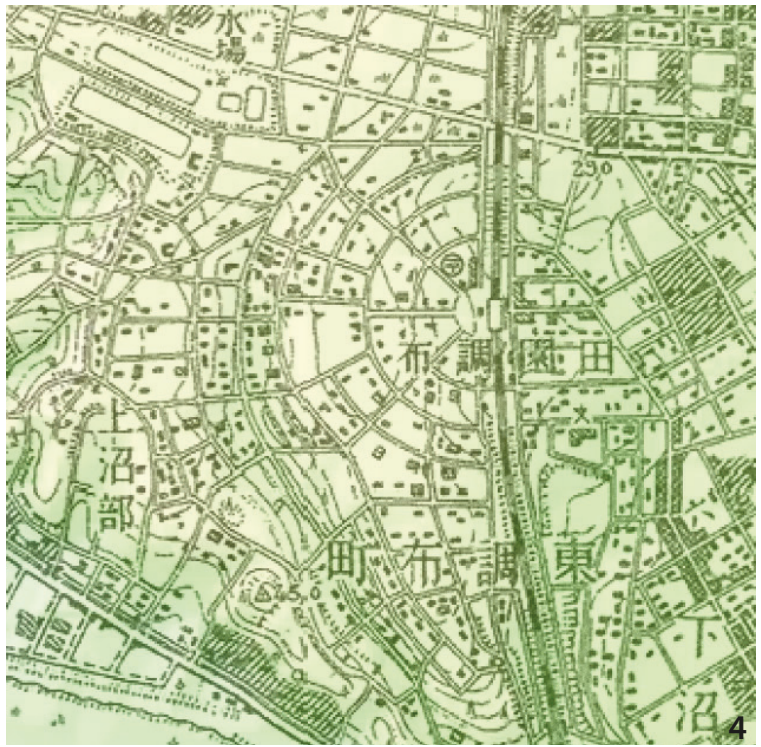

1971 special issue of Architecture Culture, titled 'Nihon no Hiroba' (Public Spaces of Japan) (Figure 5), edited by Ito, made a considerable splash.

Although, broadly speaking, the notion that 'modernisation = Westernisation' remained firmly rooted in the Japanese mind, in the real cities of Japan, the country's individuality often developed in a quite separate context. Whereas the centres of Western cities typically feature an accumulation of historical buildings of stone or brick that cannot be easily modified, in contrast, Japan's large cities had been destroyed by war or earthquakes and then rebuilt and renovated after the war. This gave rise to unique city spaces of constantly changing appearance, featuring a dynamic mix of sundry elements put together with a high degree of freedom. As this shift occurred, the concept of 'metabolism' emerged as an architectural current celebrating Japanese uniqueness, and this had a major worldwide impact. In the domain of urban planning, the Tokyo Bay Plan 1960 of Kenzo Tange startled the world with its original idea of gracefully developing a city stretching around Tokyo Bay with multiple functions located over the water. By the time of the 1964 Tokyo Olympics, expressways flying over the city's many canals and rivers had been constructed. It was images like this that led to Tokyo's new identity as a 'city of the future'.

Nevertheless, Japanese society, on the whole, continued to yearn for Westernisation and to think along Western models. The idea of catching up to and overtaking the West probably peaked around the time of the Osaka Expo 1970. This was viewed as an opportune moment to comprehensively showcase to the world the high degree of economic and technological capabilities that Japan had managed to

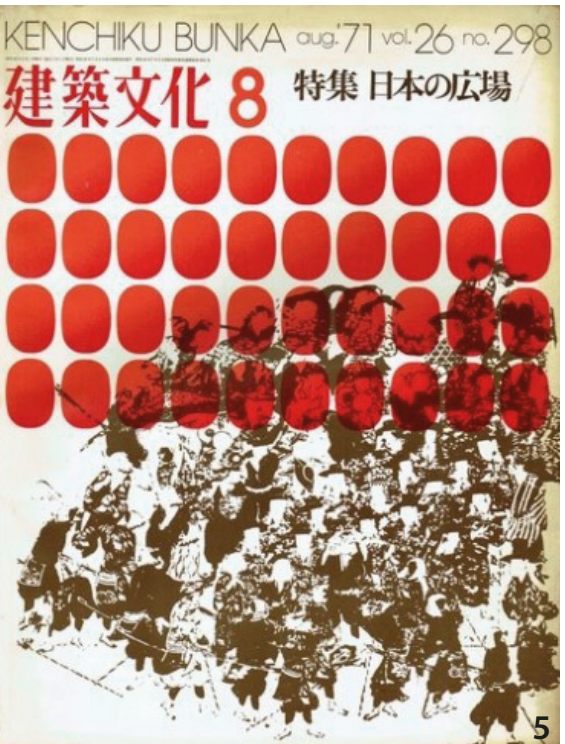

Figure 4 Den-en-chofu 1:2500 map, 1929. Figure 5 Special issue of Architecture Culture: Nihon no Hiroba, August 1971 (Source: Architecture Culture 1971). achieve by studying and learning from the West.

In this process, the work Taiyo no To (Tower of the Sun) by Taro Okamoto serves as an example of resistance to the values of Western modernism, with its freeform expression of 'Japaneseness' as a 'Jomonic' power of the masses. The unique tower was installed inside the Omatsuri Hiroba (Festival Plaza) designed by Kenzo Tange with the help of many young architects. The tower burst erect through the roof frame of the terrace. To this day, the tower remains on public display at the Expo's site as a memory of the event.

The expo of 1970 marked the pinnacle of 'modernisation = Westernisation'. While it served to express dreams for the future, in effect cities had already reached an impasse as they faced the contradictions of modernisation. The young architects that had participated hopefully in designing the Expo's 'Festival Plaza' felt frustrated at the inability to create a genuine hiroba open to the people, and many of them subsequently abandoned the problems of cities. Then a few years later, in 1973, the world was rocked by the oil crisis, which proved to be a major turning point for Japan — both economically and culturally.

\section{From the Early 1970s to the Mid-1980s}

In the 1970s, following the oil crisis, Japan entered a period of stable (but slow) economic growth. The country seemed to look back and reflect on its past of repeated destruction and construction. In the process, it gradually unearthed aspects of itself that it had long forgotten, relating to the environment (water, greenery), history, culture, landscape, and townscape; it seemed to begin turning away from quantity toward quality. It was in many ways 

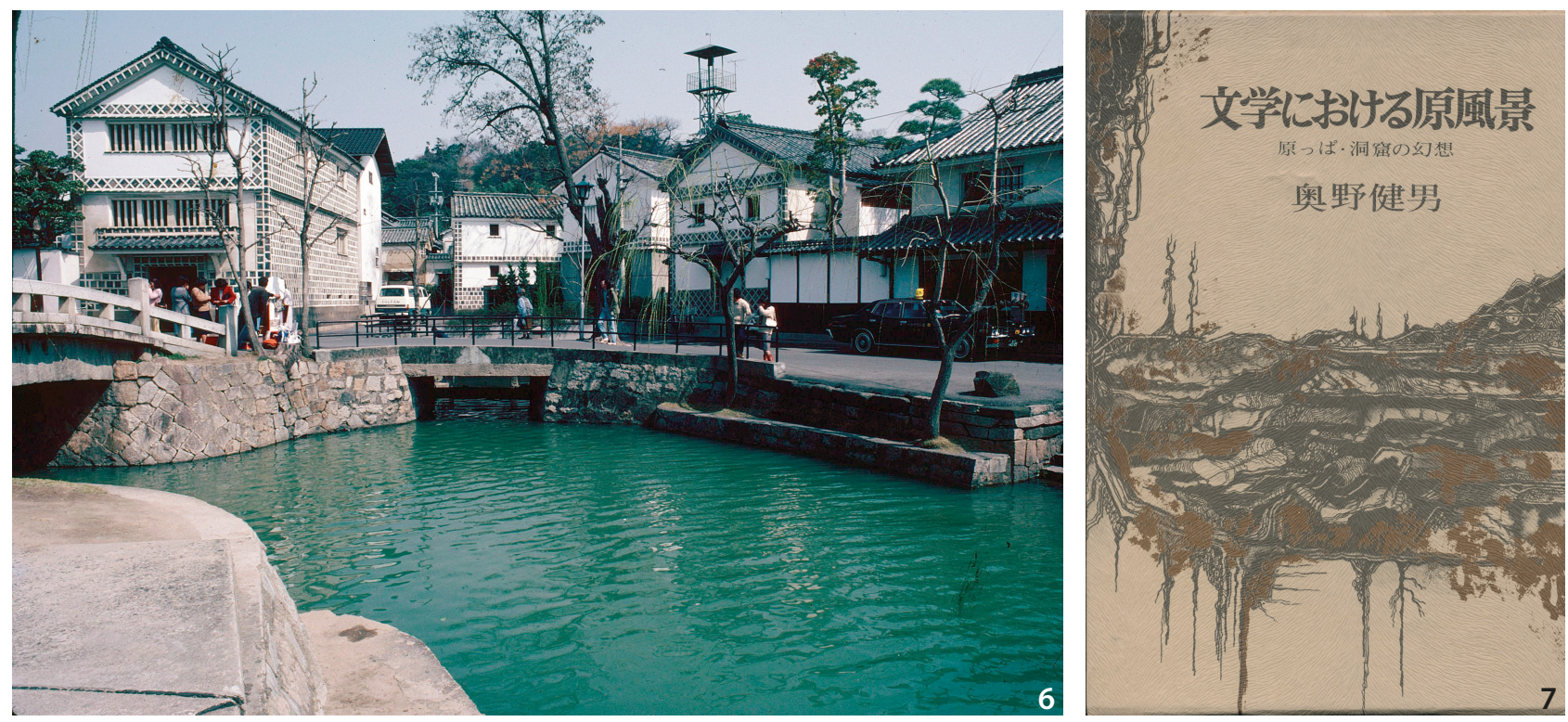

Figure 6 Kurashiki (Okayama prefecture), a pioneer in historical town conservation (Source: the author). Figure 7 Bungaku ni okeru Genfukei (Archetypal Images in Literature), Takeo Okuno, Shueisha, 1972.

an era for cultivating Japanese and local concerns.

There was a growing interest in existing urban spaces, living spaces, landscape, and community. Throughout the early 1970s, the magazine Toshi Jutaku (City Houses) focused on these concerns with a string of features on various themes.

Throughout the country, the value of urban spaces and villages featuring preserved, traditional townscapes that had escaped the waves of development attracted great interest. In 1975, the Agency for Cultural Affairs instituted a revision to the system of protecting cultural properties, making it possible to preserve such townscapes and villages under a national system, as 'Important Preservation Districts for Groups of Traditional Buildings' (Figure 6). In the early days, there was concern that preservation of old buildings would be imposed by freezing development and it would be difficult to improve living spaces, but many successful conservation projects were realised through the cooperative efforts of many towns and municipalities. The number of municipalities that utilised the new system to conserve and expand the use of old buildings and to revitalise towns has steadily increased over the years.

Shunichi Suzuki, elected Governor of Tokyo in 1979 used the slogan 'Tokyo, our hometown' in developing policies focused on water and greenery, urban beautification, landscape, and the conservation and utilisation of historical buildings.

Even in the Japanese architectural world, a major shift in thinking occurred. The 'archetypal scenery theory' proposed by Takeo Okuno (Figure 7) in 1972 exerted a strong influence on many young architects of the time. It gave rise to appealing urban theories introduced in books such as Yoshinobu Ashihara's Machinami no Bigaku (Townscape Aesthetics), Fumihiko Maki’s Miegakure-suru Toshi (Appearing and Disappearing City), and Noboru Kawazoe's Tokyo no Gen-fukei (Tokyo Archetypal Scenery). At this point, the Japanese seemed to be finally extracting themselves from the spell of Western modernism. It is fair to conclude that the 1970s marked the first stage of Japan's move toward the post-Western/non-Western.

It is also fair to say that the main forces behind the transformation of the city changed in the 1970s. There was a gradual shift from government-led, top-down urban planning, to bottom-up town-making (Machizukuri), in which citizens/residents became leading protagonists. From the citizens' campaigns of the 1960s aimed at denouncing severe environmental problems, as typified by the struggles surrounding Minamata disease (mercury poisoning in the Minamata area), there was a discernible move toward an active discovery of history and cultural values, in order to create better local environments and living spaces.

Although economic growth was slow in the early 1980s, efforts to uncover culture and history progressed, and there was a blossoming of postmodern culture. Many foreign artists and architects came to Japan, thereby helping to promote greater internationalisation. It was also a time when architects who had previously worked mainly on public buildings and housing began to design commercial 

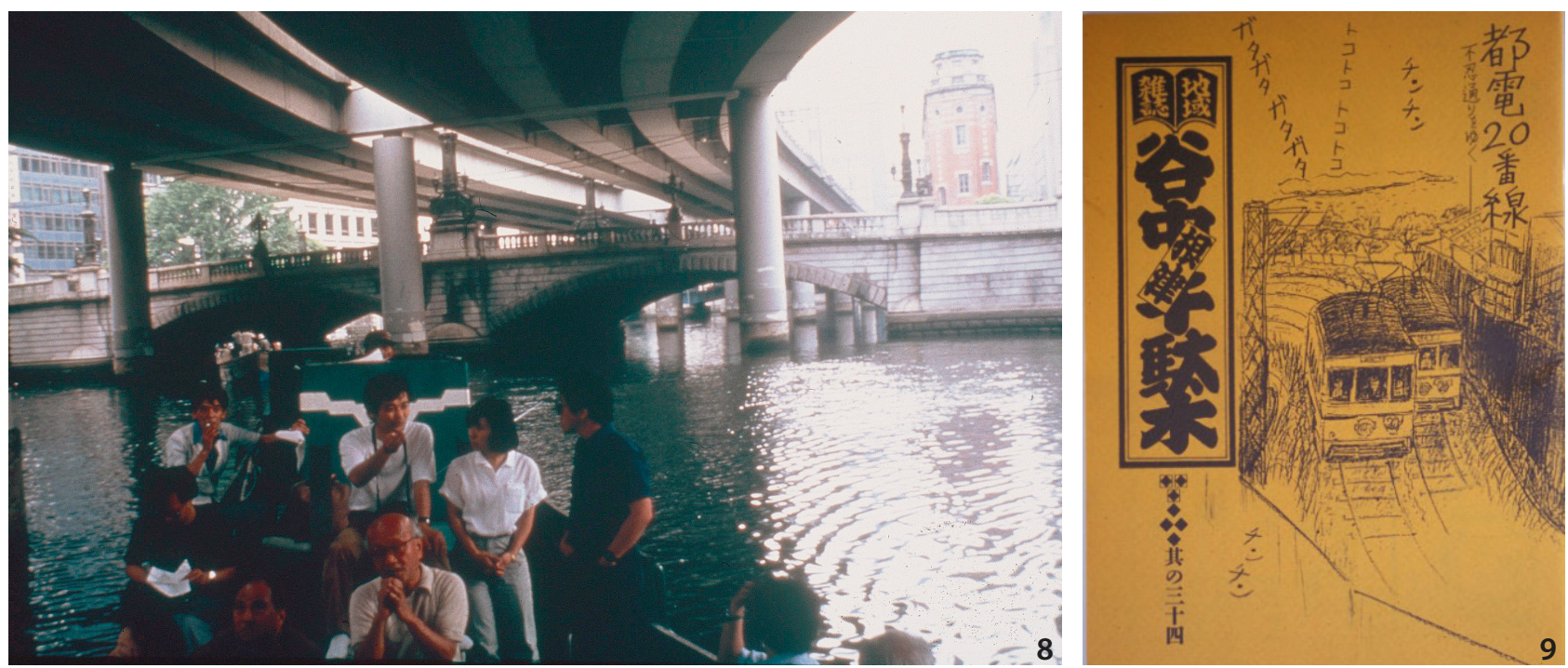

Figure 8 Survey of Tokyo water city, using a boat, by Jinnai Laboratory, begun in 1980 (Source: the author).

Figure 9 Yanesen, a pioneering community magazine.

buildings. And architects who had confined themselves exclusively to housing design once again concerned themselves with public spaces.

A variety of architectural works based on the freely conceived ideas of Japanese architects began to attract international attention. Then in the 1980s, a 'Japan boom' occurred in Europe. At this point, the whole of Japan's unique contemporary culture began to be exported to the world, as distinct subcultures, typified by anime, and in various other forms ${ }^{1}$.

Urban theory became more spirited, as the focus shifted from reflecting on development in periods of high economic growth, marked by repeated destruction and construction without regard to the characteristics of a place, to focus on the uniqueness of a place, through topos and genius loci. During this period, Tokyo was rediscovered as a 'city of water' (Figure 8), and its topography and slopes were re-appraised. Many people's eyes were opened to the virtues of characteristic Japanese urban spaces.

An 'Edo Tokyo' boom occurred in 1985-1986, influenced by continued efforts to uncover the city's Edoperiod history and to explore its cultural identity. Jinnai's book on Tokyo published in 1985 (Jinnai 1995), presented a 'spatial anthropology' of Tokyo, revealing it to be quite distinct to that of a Western city.

A magazine first published in 1984, Yanesen, focused on the three areas of Yanaka, Nezu, and Sendagi, where the historic environment of northeastern Tokyo was well preserved. This interesting local magazine attractively presented the findings of three local women, whose meticulous research uncovered a wealth of detail about local history, culture, and lifestyle. It is remarkable that a group of architects and planners that took root in the local community engaged so successfully in bottom-up townmaking with residents (Figure 9). The 1980s, which saw a wide variety of similar developments, could be seen as the second stage of Japan's move to the post-Western/nonWestern.

Yoshinobu Ashihara's The Hidden Order (1986) attracted much attention when it emerged within a burgeoning postmodern cultural milieu. The book showed that although Tokyo appears at first chaotic, made up of fragments and parts assembled at random, there is actually a hidden order; a stable structure can be discerned. Western intellectuals were somehow greatly attracted by this Japanese idea of a separated and fragmented city. Here too, concepts are perceived from the details and ideas of the city. This approach is quite different to that of Western cities, which are conceived as a whole.

\section{The 'Bubble Era' and 'Post-bubble Era'}

In the late 1980s, Japan experienced a strong economic revival, as it connected with the world's biggest markets. This resulted in an economic boom time referred to as the 'bubble era'. Together with New York and London, Tokyo had become a major global city. While the Machizukuri activities that began in the 1970s, emphasising grassroots local history, culture, and community, continued to evolve, glamorous, large-scale developments and internationalisation initiatives captured the bulk of public attention.

In line with broad shifts in the industrial structure of 


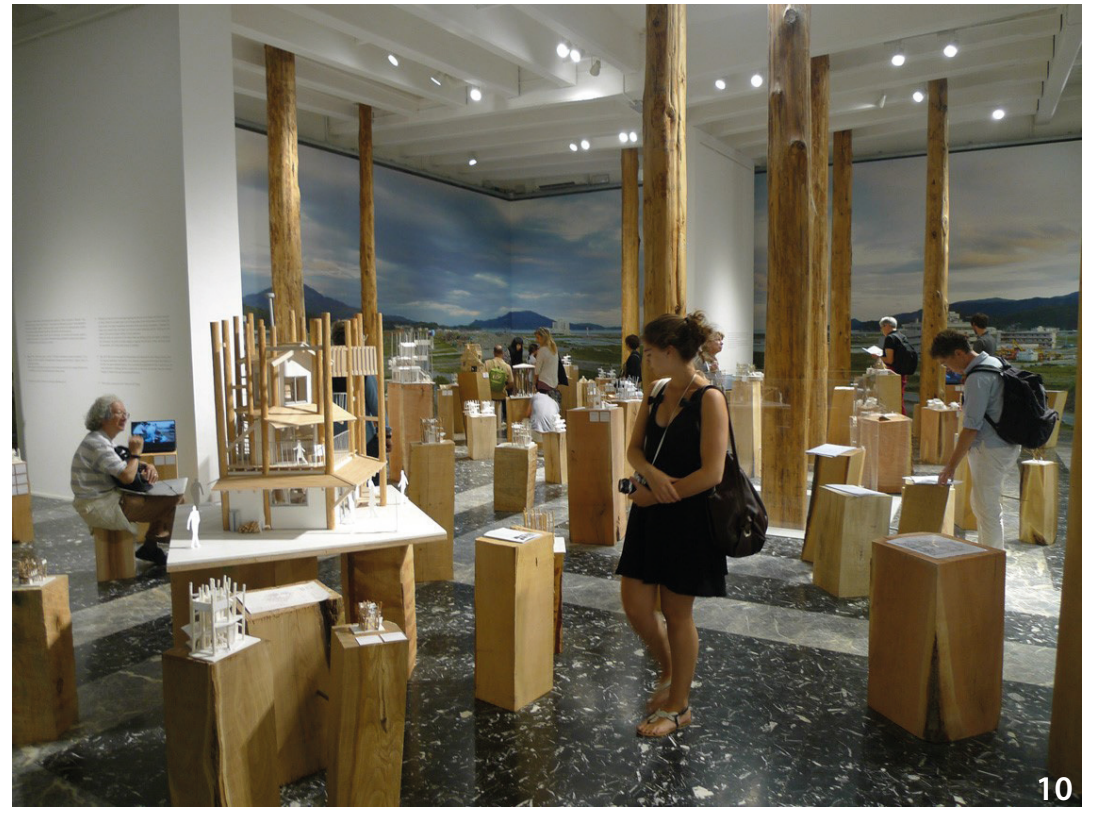

Figure 10 Exhibit 'Home-for-All', Toyo Ito, 2012 (Source: the author). cities, major changes occurred in land utilisation in harbour areas that had long served for coastal distribution and production functions. In the early 1980s, waterfront redevelopment projects were also promoted to generate new urban spaces for the new era. All such cases of redevelopment in Japan-e.g., in Hakodate, Yokohama, Tokyo, Kobe, and Osaka-were, however, modelled after the most advanced Western examples. Once again, it was difficult to escape the old habit of imitating Western culture.

In the spring of 1992, the economic bubble burst, leading us through various stages to our present circumstances. Ever since globalisation has become an increasingly strong force. Its economic logic has led to Japan's activities and resources becoming ever more concentrated in the Tokyo region, and it has worsened regional depopulation. In other cities, we have seen more and more urban degeneration and shuttered shopping districts, while urban functionality has spread to urban peripheries, resulting in the loss of rural landscape.

As Japan has become a mature society, economic growth has stopped, and the country is now facing the severe social problems of an ageing population and declining birth rate. In regional mountainous areas, population decline is now critical, threatening the survival of the communities. The number of such communities referred to as 'marginal settlements', is increasing. Since the development of sustainable cities is such an important theme, the 'compact city' concept, which originated in the UK, has been seriously debated in Japan. Hidetoshi Ono, who actively uses the term 'shrinking city' for this trend, has proposed the concept of 'fibre city', for creating networks of greenery, as a strategy to improve the environmental quality of our contracting cities.

In light of its situation, like it or not, Japan now needs to break away completely from the notion that 'modernisation = Westernisation' when it comes to development. It needs to harness all the wisdom, technology, and ideas that exist in abundance at the historical, social, and cultural levels in the cities and provinces of Japan, and it needs to develop Machizukuri and regional development that takes advantage of all these resources. Japan has now fully entered a new stage, in which it is consciously and strategically aiming for the post-Western/non-Western.

From the standpoint of the post-Western/non-Western, satoyama is another keyword used along with Machizukuri, which is rooted in the community. Satoyama, the mountain areas that extend around so many rural settlements in Japan, have been maintained and managed by the local people as shared assets, for a diversity of uses, and they are intimately connected with their livelihoods and lifestyles. In reaction to the modern concept of ownership and the logic of economic development, the idea of satoyama, as a 'common' possession, has been appreciated anew, so the word now symbolises a 'de-modernising' approach to community development.

\section{In the Wake of the Great East Japan Earthquake}

After the Great East Japan Earthquake of March 11, 2011, the importance of kizuna, interpersonal bonds, and local social networks was felt very strongly. The urge for a 
cultural identity also grew stronger.

At the Japan Pavilion at the Venice Architecture Biennale 2012, the exhibit titled 'Home-for-All', curated by Toyo Ito, was highly acclaimed, winning a Golden Lion Award (Figure 10). At various disaster-affected locations along the Sanriku coast, a debate arose about the ties between human beings, local autonomy, and the importance of 'territory', giving rise to a movement aimed at breaking away from an economic structure that is dependent on large cities such as Tokyo.

Given that demands for a sustainable society are growing stronger at this early stage of the $21^{\text {st }}$ century, the challenge of 'preserving the memories of cities and communities' is becoming increasingly urgent. Here too, a new debate along post-Western/non-Western lines is emerging.

In Western cities, the mere destruction of historical buildings is associated with a loss of cultural identity, so people tend to care deeply about preservation. Formulating policies for conserving historical districts is now seen as a modern feature of Western countries, and such conservation is taken for granted in the developments of a city's economy.

In Japan on the other hand, despite some progress in the conservation of traditional townscapes under a national system, including some notable major successes, these efforts have been very limited when considering Japan as a whole. Many cities have no surviving historical districts at all; they are characterless urban districts exposed to the wave of modernisation. In big cities, where economic imperatives took priority over all other values, some efforts have been made to preserve old buildings, but in the great majority of cases, old buildings have been destroyed, to be replaced by much larger, more functional buildings.

Notwithstanding this difference with the West, new ways of thinking have emerged. One characteristic of Japanese culture is that even if a building is lost temporarily, the 'memories of the land' on which it stood tend to be preserved on various levels. Attention is paid to details such as the undulation of terrain, uneven topography, hills, cliff lines, sloping green spaces, springs, sacred places, 'power spots', various kinds of waterfronts (rivers, moats, ponds, sea), old river courses that have become drains, and alleyways, and a move to understand the features of buildings and townscapes by exploring the relationships with these kinds of surrounding elements has arisen. Clearly, this is somewhat different to the architecture-centric historical conservation of Western cities. It is now recognised that what is fundamental to Japan is a 'culture of cities' that emphasises coexistence with nature.

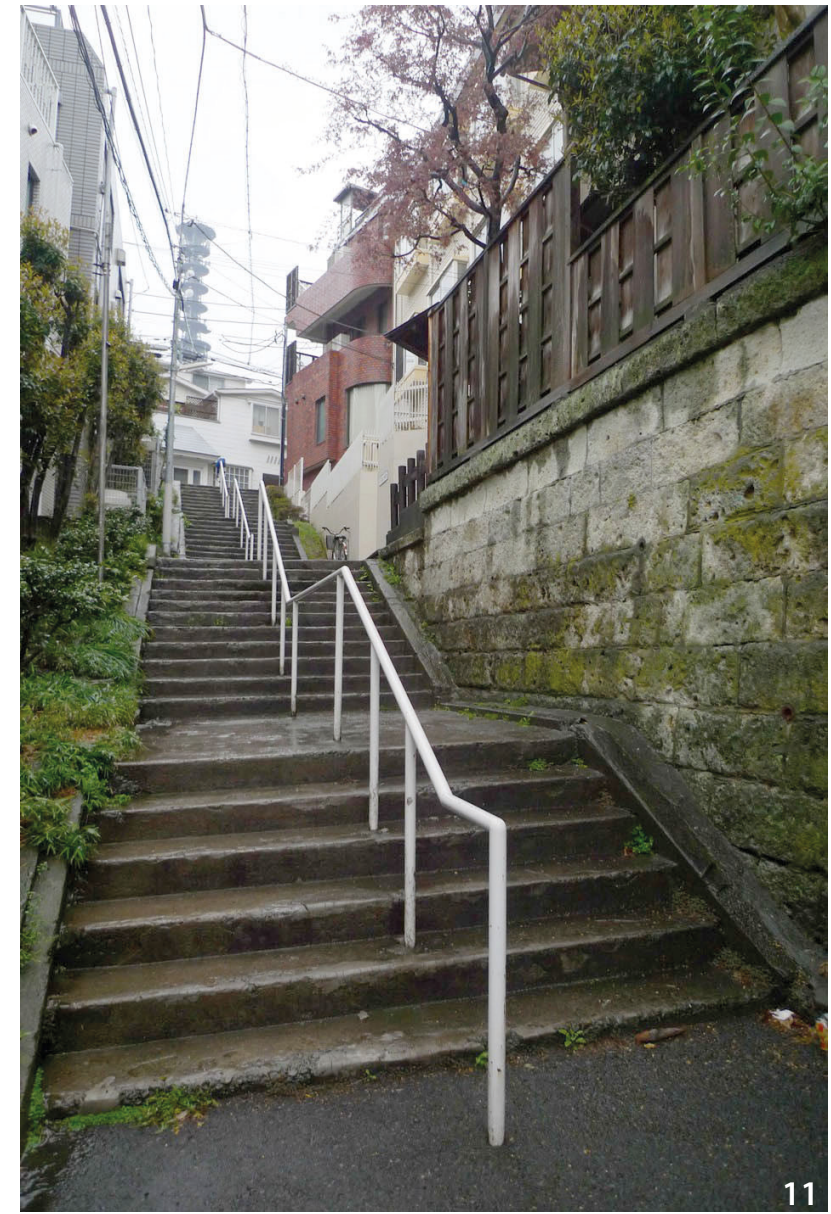

Figure 11 Yotsuya Araki-cho, with its uneven topography, a sacred place for the Tokyo Suribachi Gakkai (Mortar Society) (Source: the author).

Buildings in Japan have a useful life of 30 years on average, which is short, so buildings are frequently replaced, resulting in dramatic changes to landscape and skyline. In light of this fact, it is very interesting to note a pronounced tendency for people to take an interest in stable elements such as topography and terrain. The Tokyo Suribachi Gakkai (Mortar Society), which takes great interest in Tokyo's uneven topography-its members walking around and fanatically observe the city's distinctive urban spaces-is growing in popularity, very much reflecting today's Tokyo (Figure 11).

There is also a growing recognition of the importance of the 'soft' elements, or intangible aspects, of a city, such as human relations between locals, community, and festivals. Even in the projects aimed at the recovery and revival of cities and settlements that were devastated by the tsunami, the preservation of these kinds of memories, which are deeply tied to the cultural identity of local inhabitants, is seen as important.

In connection with this shift in values, there is a 


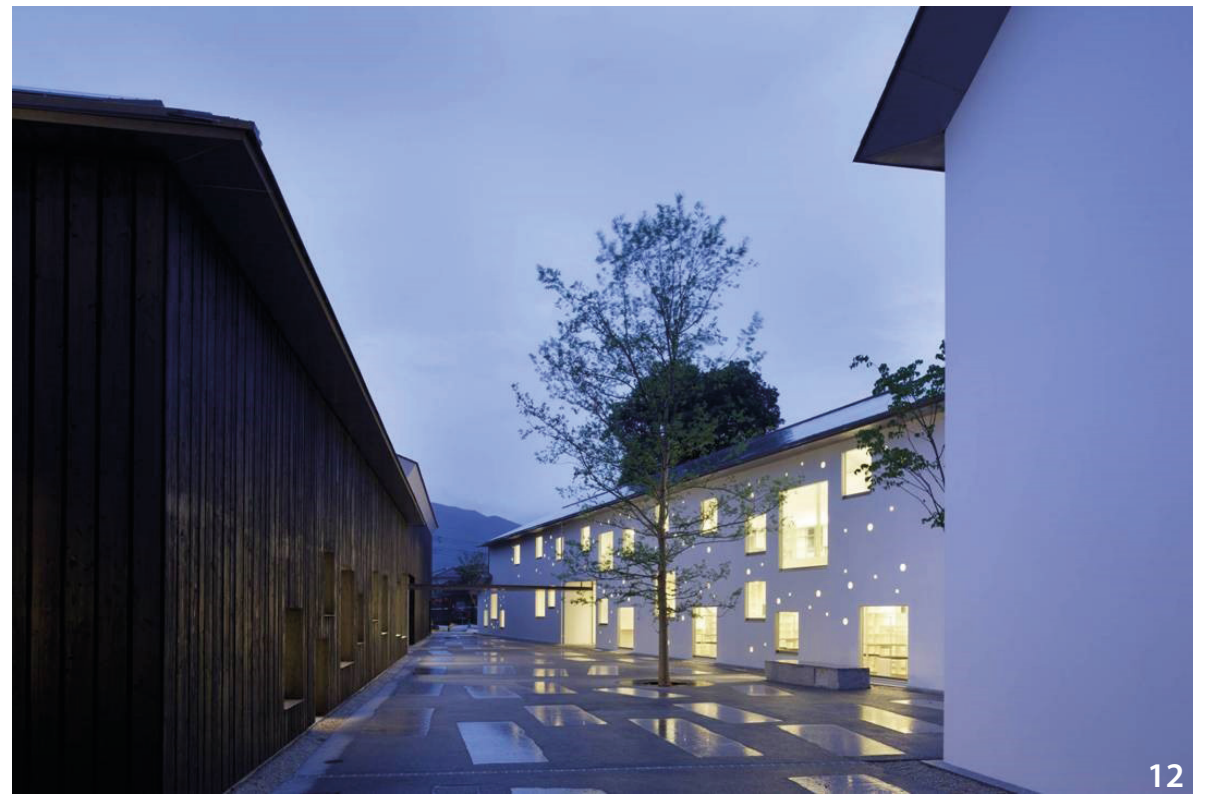

Figure 12 Makabe Denshokan at dusk (Source: Satoru Shigeta). movement that seeks to find positive meaning in the state of high-density urban districts with many wooden buildings, which tend to be seen negatively by government bodies because they are considered dangerous in terms of disaster prevention. At the Japan Pavilion of Venice Architecture Biennale 2010, an exhibit titled 'Tokyo Metabolising', curated by Ko Kitayama, was admired for showing that despite the absence of any overall plan, Tokyo is characterised by an unfolding of autonomous environmental planning efforts in each part of the city, in bottom-up fashion, unlike Western cities, which are created based on a top-down concept, originating with the ruling power of the city. Since connections within a community are so important, common spaces are skillfully positioned amongst residents, and meaningful gaps are wisely placed to create flexible living environments.

The Yanaka district mentioned earlier is, as always, an acclaimed example of this. Its extensive alleyways and other small-scale spaces are much admired internationally (Radovic and Boontham 2012; Imai 2017).

Shimokitazawa, which is also internationally acclaimed, by a former mayor of Curitiba (southern Brazil) amongst others, is also characterised by the linking of small-scale spaces to create 'migratory' pathways. Despite a lack of old buildings, there is a distinct sense of history and place.

In a country prone to fire disaster such as Japan, disaster prevention tends to become a force for community solidarity and an opportunity for town planning. Residents work together to imagine the possible consequences of an earthquake and create a recovery plan in advance. This process has proven to be very effective in promoting strong ties between the people of the community.

\section{Examples of Bottom-up Town-making (Machizukuri)}

Japan extends over a vast distance from north to south and its topography, and natural conditions are highly varied. Each of its regions has therefore developed its own culture. Now that they have broken the spell of 'modernisation $=$ Westernisation', Japanese are taking advantage of the unique qualities of the land throughout the country to develop a wide variety of bottom-up forms of town planning, based on re-evaluations of nature, history, culture (food, crafts, housing, and townscape).

Globalisation, if looked at another way, with fresh eyes and a knowledge of global culture, is something that offers us the opportunity to rediscover and re-evaluate the unique cultural values that lie dormant and untapped in each particular region.

The number of historical districts designated as 'Important Preservation Districts for Groups of Traditional Buildings' has increased in recent years, reaching a total of 114. These characteristic urban spaces are expected to accelerate tourism. The overall design of Makabe Denshokan, a community centre created by architects Makoto Watanabe and Yoko Kinoshita, was developed through repeated workshops with local citizens on the subject of newly built public buildings in Makabe-a town with important historical buildings. Through this process, architectural vocabularies to shape the image of the town were determined and combined. This project has captured 


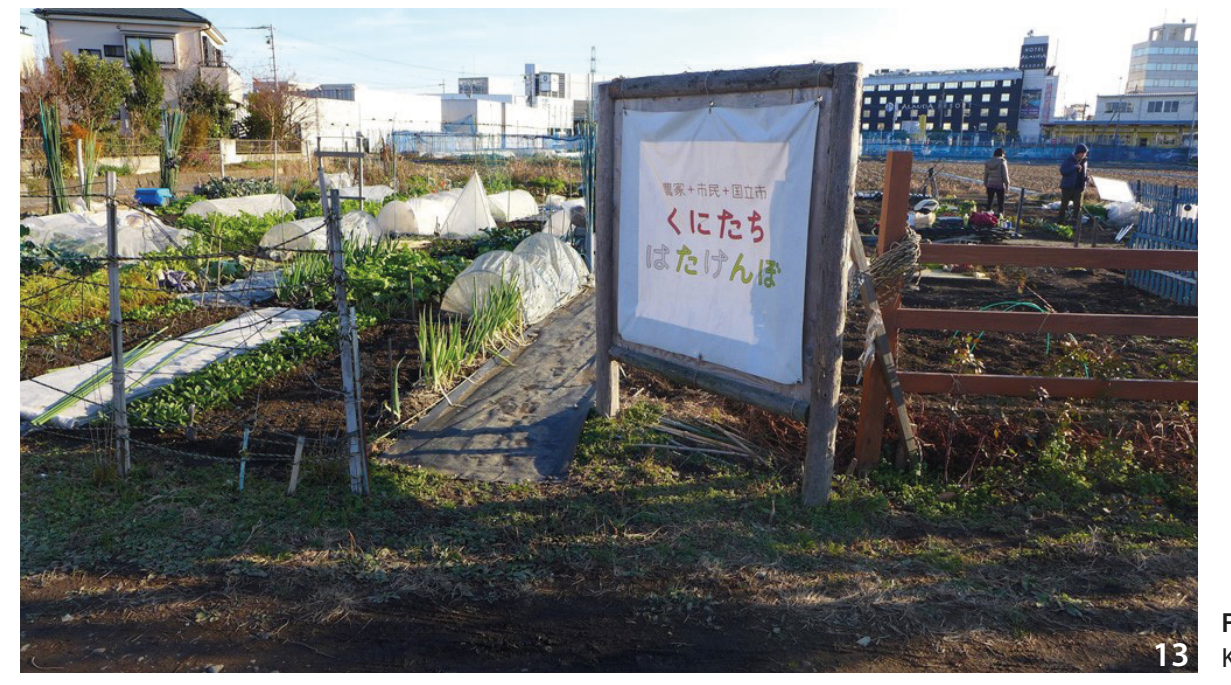

Figure 13 Urban agricultural activity in Kunitachi (Source: the author).

widespread interest as a Japanese-style example of how history can be inherited (Figure 12).

Even within the megalopolis of Tokyo, several characteristically Japanese bottom-up style town planning activities-of a kind not seen in Europe or America-have been observed in recent years. One example is the Kunitachi development project in the western suburbs of Tokyo. It is known as a modern university town that extends over a large area opposite the (JR) railway station. Along the cliff line slightly to the south, there are, in fact, old settlements, below which extensive paddy fields and other kinds of farmland can be seen. It is within this setting that citizens and universities engage in rural community's activity, leveraging the surviving agriculture traditions of the city (Figure 13). In front of the station, there are signs of urban-rural collaboration, such as the establishment of Italian restaurants run on the principle of 'local production, local consumption', as well as 'antenna shops' selling foodstuffs.

Another interesting movement is in the shitamachi (low-lying, downtown) district on the east side of the Sumida River, relatively distant from the heart of Tokyo. The Kiyosumi Shirakawa district of Fukagawa, in Koto Ward, is a 'city of water', surrounded by canals. The area once prospered because of its timber yards; it was a lively town with a high concentration of craftsmen working in wood processing and printing facilities. The district is also unique for its many temples. For a while, after the timber yards moved, the area was stagnant, but it has been revitalised significantly over the past five years.

Numerous art galleries have appeared in renovated ground floor spaces of old buildings that are larger than the regular machiya townhouses, and in the past few years coffee shops have been opening, one after another, often in spaces with high ceilings. Like this, a charming neighbourhood has emerged; a fusion of traditional shitamachi atmosphere and the latest urban cultural trends (Figure 14). In terms of both its 'hardware' and 'software' aspects, the social and cultural stock of this district has been maximised. In the case of both art galleries and coffee shops, Western elements have been freely accepted and placed with a Japanese-style social and cultural setting, giving rise to a unique world that can only be found right here, right now.

The concept of renovating and re-purposing old buildings that are not cultural assets and that do not have any other special significance seems to be spreading rapidly amongst the young generation of architects. Instead of aiming at a glamorous, striking architectural creation, they have demonstrated a strong commitment to planning and design, making the most of the location's features, which generates new relationships and seeks sustainability-a very appropriate approach to the new age we live in Japanese-style renovation culture is definitely blossoming.

At the Japan Pavilion of the Venice Architecture Biennale 2016, the exhibit titled 'en: art of nexus' curated by Yoshiyuki Yamana, posed the question of how architects should respond to Japan's current circumstances, in which continued economic slowdown and the occurrence of the Great East Japan Earthquake have forced changes in values in all kinds of fields (Figure 15). The exhibit presents a profusion of original ideas, based on flexible concepts that are unique to contemporary Japanese architects. It features a shared house that fosters relationships between people living in a highly fluid society, and rich spaces that make the accumulation of time deeply felt through the combination of old and new elements and materials. 

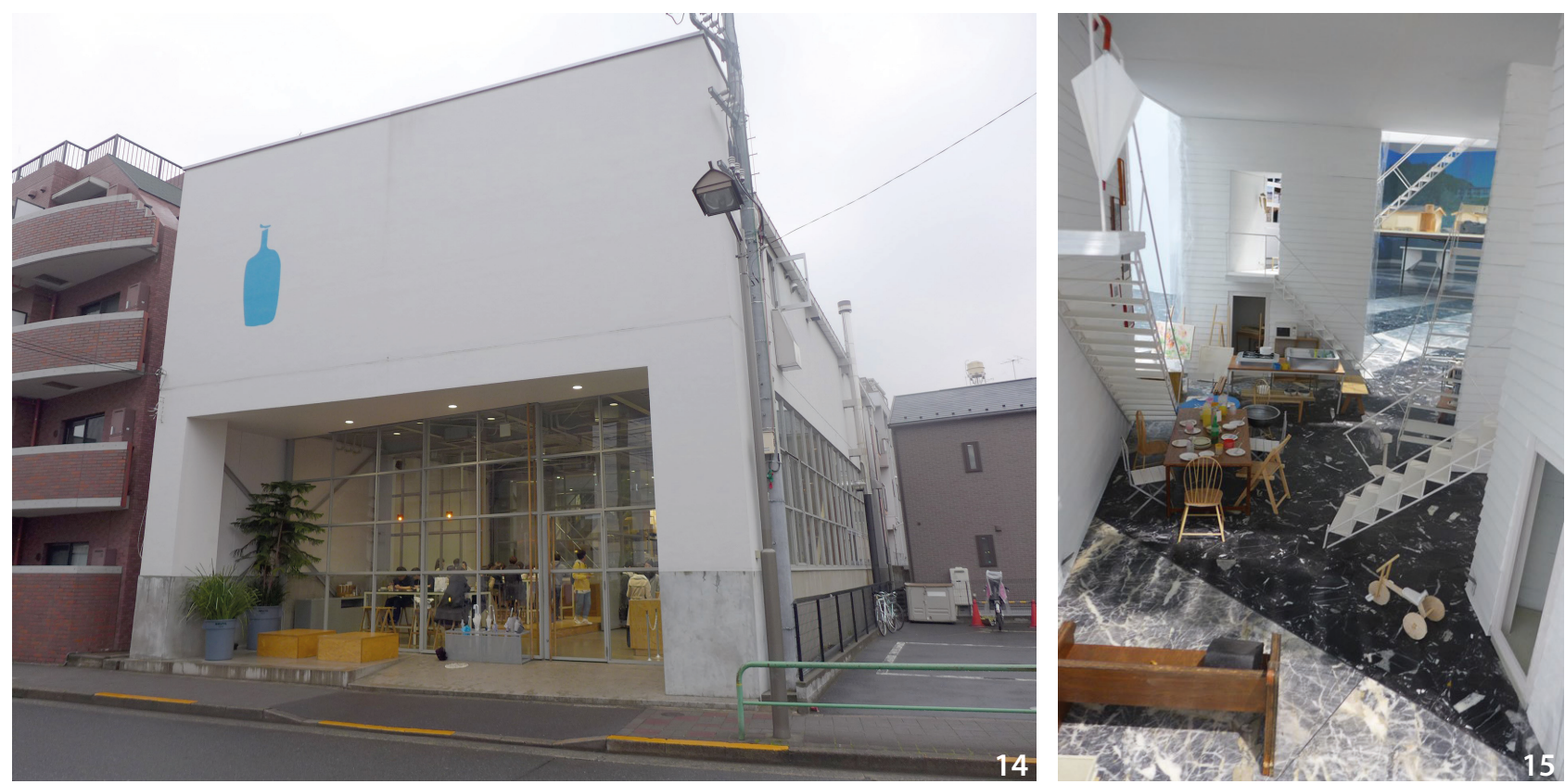

Figure $14 \mathrm{~A}$ coffee shop in a converted warehouse in Kiyosumi Shirakawa (Source: the author). Figure 15 Share house in "En: Art of Nexus" exhibition (Source: the author).

\section{Conclusion}

In this article, the phasing evolutions of architectural and urban design practices in Japan, which have led to the idea so called 'post-Western/non-Western' have been reviewed from historical perspectives. The following article provided by Takashi Ariga explores current attempts of 'Japanese Machizukuri' as one of the salient fields of 'post-Western/ non-Western' by means of examining both their tangible and non-tangible correlations to the contextual values of local communities.

As I have mentioned before, from the 1970s Japanese people gradually began to leave the idea of catching up and overtaking the West and started developing their own way to proceed. In the 1980s, 1990s and after the 2000s, passing several stages, we could observe the steady and gradual process to pursuit the Japanese cultural identity. Contemporary Japanese culture-different from Western approach-began to be appreciated all over the world. The richness of nature, the particular Japanese history and its specific culture developed through delicate senses were re-evaluated. At the same time, the cultural values of the historic urban space and townscape were rediscovered. We should stress the importance of the re-evaluation and rediscovery not only of the physical spatial logic and order in the existing cities but also of the human relationships in the urban community.

The idea and method of Machizukuri were born and developed utilizing these hard and soft resources. The tendency of such kind of search for Japanese style architecture and urbanism became clearer after 2000. Looking at how the exhibitions organised in the Japan Pavilion of Venice Architecture Biennale had strong impacts on the Western visitors, we can understand that Japan produces steadily important fruits based on the values suitable to the new era from the free standing position oriented toward the post-Western/non-Western.

\section{Notes}

1. International Conference for the $150^{\text {th }}$ Anniversary of Japanese-Italian Relations, 'Lost in Translation? Japan in Italian Cultural Life', Ca'Foscari University, Venice, 13-15 October, 2016.

\section{References}

Imai, Hide. 2017. Tokyo Roji: The Diversity and Versatility of Alleys in a City in Transition. Routledge, Oxford.

Jinnai, Hidenobu. 1995. Tokyo: A Spatial Anthropology. University of California Press.

Ogata Mituhiko. 1980. Towns Meiji, Taisho, Showa. The Changing Process of the Japanese Modern Cities Seen from the Postcards-1902-1941-Part of Kanto-Region. Institute of Urban Study.

Radovic, Darko and Davisi Boontham. 2012. Small Tokyo. Frick studio Tokyo.

Tokyo Municiple Office, ed. 1935. Guide of Parks. Tokyo: Tokyo Municiple Office. 